Delft University of Technology

\title{
Experimental identification of the dynamic behaviour of pile-soil system installed by means of three different pile-driving techniques
}

Tsetas, Athanasios; Gómez, Sergio S.; Tsouvalas, Apostolos; van Beek, Kees; Sadeghi Tehrani, F.; Kementzetzidis, Evangelos; Pisanò, Federico; Elkadi, Ahmed; Segeren, Maxim; Molenkamp, Timo

DOI

10.47964/1120.9245.20367

\section{Publication date}

2020

Document Version

Final published version

Published in

EXPERIMENTAL IDENTIFICATION OF THE DYNAMIC BEHAVIOUR OF PILE-SOIL SYSTEM INSTALLED BY MEANS OF THREE DIFFERENT PILE-DRIVING TECHNIQUES

\section{Citation (APA)}

Tsetas, A., Gómez, S. S., Tsouvalas, A., van Beek, K., Sadeghi Tehrani, F., Kementzetzidis, E., Pisanò, F., Elkadi, A., Segeren, M., Molenkamp, T., \& Metrikine, A. V. (2020). Experimental identification of the dynamic behaviour of pile-soil system installed by means of three different pile-driving techniques. In $M$. Papadrakakis, M. Fragiadakis, \& C. Papadimitriou (Eds.), EXPERIMENTAL IDENTIFICATION OF THE DYNAMIC BEHAVIOUR OF PILE-SOIL SYSTEM INSTALLED BY MEANS OF THREE DIFFERENT PILEDRIVING TECHNIQUES: Athens, Greece, 23-26 November 2020 (Vol. 2, pp. 3005-3015). (EASD Procedia). European Association for Structural Dynamics (EASD). https://doi.org/10.47964/1120.9245.20367

Important note

To cite this publication, please use the final published version (if applicable).

Please check the document version above. 
EASD

Procedia
EURODYN 2020

XI International Conference on Structural Dynamics

M. Papadrakakis, M. Fragiadakis, C. Papadimitriou (eds.)

\title{
EXPERIMENTAL IDENTIFICATION OF THE DYNAMIC BEHAVIOUR OF PILE-SOIL SYSTEM INSTALLED BY MEANS OF THREE DIFFERENT PILE-DRIVING TECHNIQUES
}

\author{
Athanasios Tsetas, Sergio S. Gómez, Apostolos Tsouvalas, Kees van Beek, Faraz S. \\ Tehrani, Evangelos Kementzetzidis, Federico Pisan`o, Ahmed Elkadi, Maxim Segeren, \\ Timo Molenkamp, Andrei V. Metrikine
}

Faculty of Civil Engineering and Geosciences, Delft University of Technology, Stevinweg 1, 2628 CN Delft, The Netherlands

e-mail: $\{$ A.Tsetas, s.sanchezgomez-1, A.Tsouvalas, C.vanBeek, F.Tehrani, E.Kementzetzidis, F.Pisano, A.S.K.Elkadi, M.L.A.Segeren, T.Molenkamp, A.Metrikine\} @ tudelft.nl

Keywords: Soil-structure interaction, pile driving, experimental testing, system identification, installation effects

\begin{abstract}
A novel pile-driving technique, named Gentle Driving of Piles (GDP), that combines axial low-frequency and torsional high-frequency vibrations has been developed and tested recently. During the experimental campaign, several piles were installed onshore, making use of the GDP shaker. Besides those, a number of additional piles were installed using conventional pile-driving techniques, i.e. impact piling and axial vibratory driving. After the completion of the installation phase, the installed piles have been subjected to impact hammer tests with the following goals. First, the in-situ dynamic properties of the pile-soil system have been identified. Second, the post-installation soil state has been investigated, along with its evolution in time for each pile driving scenario. Preliminary analyses, of the data collected during the impact tests show dissimilar trends in the overall dynamic response between the piles installed with impact hammer and those installed with the axial and the GDP shakers. This observation suggests a difference in the post-installation dynamic behaviour of the pile-soil systems related to different pile-driving techniques. In this paper, a first attempt is made to identify the differences in the overall pile-soil dynamic behaviour of the piles installed by means of the three different pile-driving techniques.
\end{abstract}




\section{INTRODUCTION}

The offshore wind industry plays a major role in the energy transition. Due to the sustainability targets set at international level, the installed capacity of offshore wind turbines is growing, leading to greater depths and distances to shore [7]. In that framework the foundations of offshore wind turbines are also affected by this consistent progression challenge. Monopiles are the most common foundations used for offshore wind turbines in shallow waters, like the North Sea [6]. Various alternative foundation concepts do exist, yet these substructures remain the most favorable choice due to simplicity of manufacture, ease of the installation procedure, robustness and proven reliability $[1,5]$.

Currently, impact pilling is the most common method for the installation of monopiles in the offshore environment [8]. However, the latter installation method engenders several issues that require further consideration. The major drawbacks are the high levels of noise generated during pile driving [9], which may be harmful for the aquatic species, and the large stresses developed at the pile head during hammer impact, that can reduce the structural life-time of the monopile due to fatigue [2]. Consequently, an alternative pile driving technique that can mitigate the noise emissions and does not peril the fatigue life of the structure, without compromise of the driving efficiency and the pile bearing capacity, has been a growing need. To that end, a novel pile-driving technique, named Gentle Driving of Piles (GDP), that aims to accomplish the stated objectives, has been recently developed. This technique is based on simultaneous application of low-frequency axial vibrations and high-frequency torsional vibrations at low amplitudes.

To test the novel pile driving technique, an experimental campaign was designed and executed in a site of medium to medium-dense sand. This experimental campaign encompassed the installation of several piles by means of three distinct pile driving techniques; namely, impact pilling, axial vibratory driving and GDP. Following the installation tests, that were concluded to be successful, further investigation was considered necessary to provide evidence that the bearing capacity and the dynamic properties of the pile-soil system have not been compromised and are within acceptable limits for operation. To this end, in the post-installation phase, lateral loading tests and impact tests with an instrumented hammer were conducted, in order to investigate further the effect of each installation method on the behaviour of the pile-soil system. More specifically, the response in operational conditions, the vibration characteristics and the temporal evolution of the dynamic properties of the pile-soil system are to be examined, in accordance with the aforementioned experimental tests. The present work is focused upon the instrumented hammer impact tests, in order to examine the dynamic behaviour of the installed piles in terms of prior- and post-loading response, temporal evolution of the system properties and influence of the respective installation method. At this point it was observed for the first time that the method of installation can have significant influence on the vibration characteristics of the system such as damping and dynamic stiffness.

This paper is structured as follows. In Section 2, the experimental tests and the identification procedure followed are described. Onwards, in Section 3 a collection of the most representative results are presented, along with some observations and relevant conclusions. In Section 4, the main conclusions accompanied by the research questions to be addressed in the near future are outlined.

\section{EXPERIMENTAL TESTS AND IDENTIFICATION PROCEDURE}

During the installation phase of the experimental campaign, several piles were installed by means of impact pilling, axial vibratory driving and GDP techniques. The dimensions of the 
tests piles and the reaction pile are given in Table 1.

\begin{tabular}{ccc}
\hline Pile Geometry & Test piles [m] & Reaction pile [m] \\
\hline Length & 10 & 10 \\
Outer diameter & 0.762 & 1.6 \\
Wall thickness & 0.0159 & 0.02 \\
\hline
\end{tabular}

Table 1: Geometrical characteristics of the piles.

Evidently, since the main objective of the experimental campaign was the proof of concept of the GDP method, the majority of the piles were installed by means of the latter method. Furthermore, the rest of the piles in the experimental site were installed by impact and axial vibratory driving, the two conventional and currently most established installation methods [3]. The latter were mainly chosen to serve as reference cases, since they are vastly used in engineering applications and their features during and post-installation are considered to be known. The configuration of the installed piles is shown in Figure 1. The position of the 8 piles installed around the reaction pile is displayed, while the latter was used as a support for the post-installation lateral tests loading apparatus.

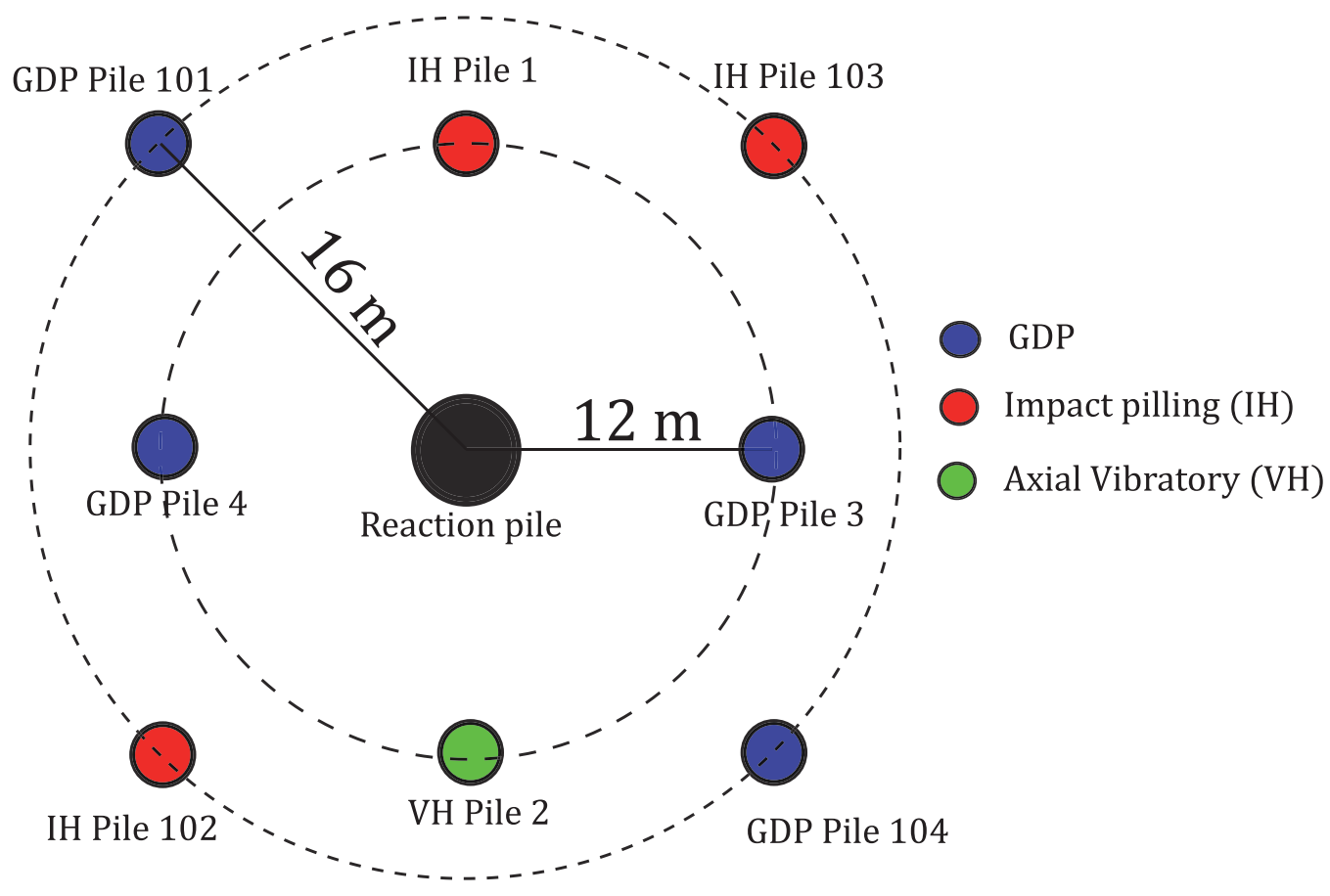

Figure 1: Pile layout

As already presented in Table 1, the test piles were 10 meters long, with final embedment depth of 8 meters. Accordingly, the height above the ground level was 2 meters, such that an adequate part of the pile could be used to mount the loading frame for the lateral loading tests. 


\subsection{Experimental set-up}

In order to perform the impact hammer tests, 2 PCB tri-axial accelerometers and an instrumented impact hammer were used. The tests were performed on all the installed piles using the instrumentation set-up displayed in Figure 2.

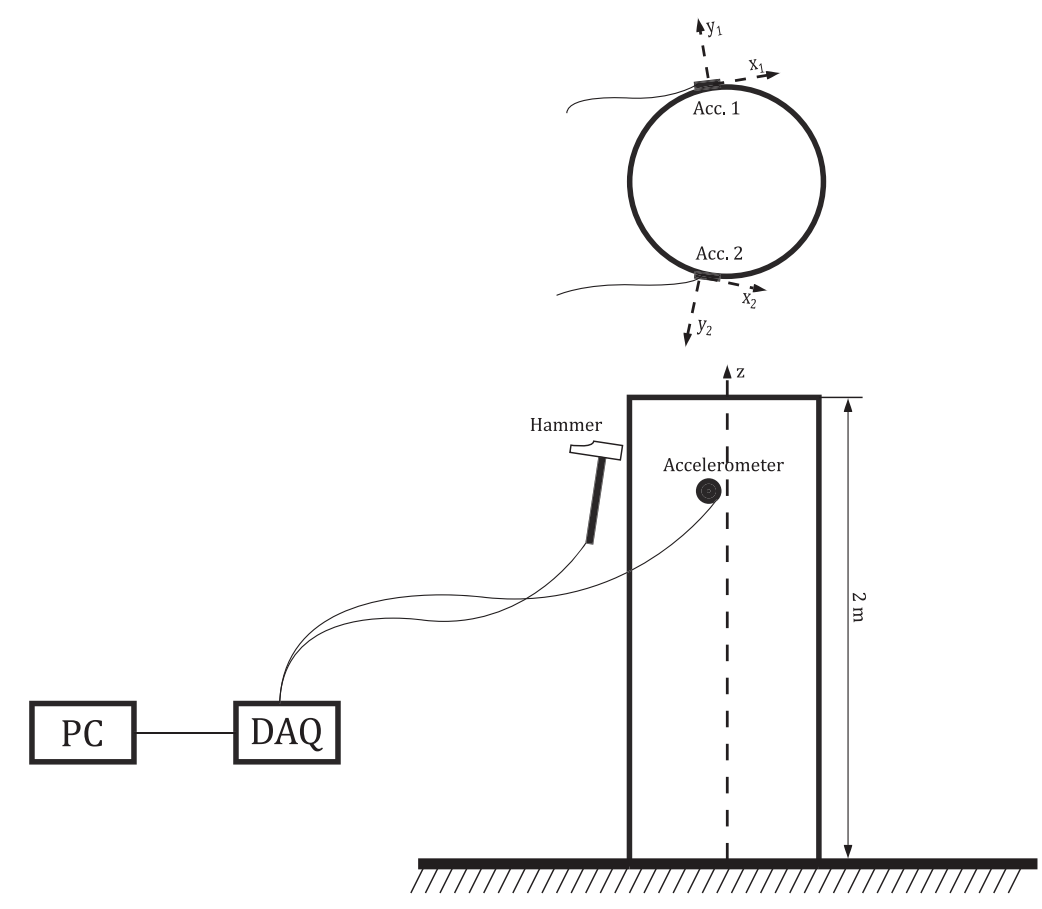

Figure 2: Experimental set-up and pile instrumentation

The instrumented hammer was used to excite the pile at two different locations and with different impact direction. First, the hammer was impacted horizontally, as shown in Figure 2 and at 1.5 meters above the ground surface. Each test was comprised of three distinct hits, in the same location and direction, in order to ensure the consistency of the measurements. In the same manner, hammer impact tests were repeated with an impact force applied along $z$-direction, at the top of the pile and in the same vertical line that the horizontal impacts were performed.

The accelerometers were mounted to the outer wall of the pile at the same height with the location of the horizontal hammer impacts, 1.5 meters from the ground surface. Acceleration data were registered in $x, y$ and $z$ directions simultaneously, with a sampling frequency that was set to $16 \mathrm{kHz}$ for all tests.

During a period of two weeks, three hammer impact tests took place, one week apart from each other and in parallel with the lateral loading tests. The latter tests, conducted in parallel with the impact tests due to time constrains, were detrimental for the direct comparison of all the hammer tests, but did allow for a comparison of the installed piles in groups. Piles that were tested in analogous circumstances are grouped together and conclusions are drawn based on the features of each respective pile group.

In the present work two groups will be considered, one group including the four piles seen in Figure 1 at a radial distance of 16 meters from the reaction pile. These piles had been laterally loaded before the start of the impact hammer test, to mimic loading conditions similar to the ones encountered in offshore environments. This group was chosen on the basis that all piles had experienced lateral loading already and piles installed by two different techniques 
comprise the first group, namely the impact-driven and the GDP piles. Thus, without drawing a conclusion with respect to the loading, the time evolution of the system properties and the effect of the installation method could be identified. The second group is comprised of two instrumented piles driven by axial vibratory driving and the GDP technique. At the first day of the hammer tests, both piles were not loaded, so a comparison was performed based on the data obtained from the testing on the first and last day of the experiments. In essence, the preand post-loading behaviours were compared, to showcase the effect of loading on the two piles driven with different techniques.

\subsection{Identification procedure of the main system parameters}

In this work, the half-power Band-width method (HPBW) is used to identify the main pilesoil system parameters. A natural frequency of the system can be obtained based on the location of a distinct peak in the acceleration frequency-response function (FRF) and its respective equivalent viscous damping ratio can be quantified accordingly.

The quality factor $Q$ and the frequency ratio in resonance $\Omega_{\text {res }}$ of a damped system with viscous damping ratio $\xi$, are defined in a classical manner:

$$
Q=\frac{\Delta \Omega_{\frac{1}{2}}}{\Omega_{\mathrm{res}}}=\frac{\Omega_{\frac{1}{2}}^{+}-\Omega_{\frac{1}{2}}^{-}}{\Omega_{\mathrm{res}}} ; \quad \Omega_{\mathrm{res}}=\sqrt{1-2 \xi^{2}},
$$

in which $\Omega_{\frac{1}{2}}^{+}$and $\Omega_{\frac{1}{2}}^{-}$correspond to the frequencies at which the PSD function is half of the maximum value. A general expression for the damping ratio of a SDoF system can be obtained in terms of the quality factor, as follows [4]:

$$
\xi=\frac{1}{\sqrt{2}} \sqrt{\frac{\sqrt{-Q^{4}+4 Q^{2}+4}-2}{\sqrt{-Q^{4}+4 Q^{4}+4}}}
$$

Generally, for low-damped systems, it can be assumed that $Q<<1$. In these cases, the damping ratio can be approximated by the following expression:

$$
\xi \approx \frac{1}{2} Q=\frac{\Delta \Omega_{\frac{1}{2}}}{2 \Omega_{\mathrm{res}}} .
$$

This procedure is used in Section 3 to compute the selected natural frequencies and the equivalent damping ratios of the tested piles.

\section{RESULTS}

In the current section the power spectral density graphs (PSD) are presented for the selected 4 out of 8 piles, organized in a consistent manner as presented in subsection 2.1 to draw the relevant conclusions. The following graphs have been produced using the acceleration response measured along the $y$-direction of each sensor, during the lateral hammer impact tests, as shown in Figure 2. Each pair of simultaneous recordings for each hammer impact was averaged prior to signal analysis. Subsequently, the acceleration frequency-response functions from the 3 lateral hammer impacts per day were averaged. Finally, the averaged power spectral density $S_{y y}$ of the pile-soil system at each day, for all responses and only lateral impacts, was obtained.

In Figure 3, the power spectral density for Pile IH-103, for each of the 3 testing days can be seen. Apparently, the PSD's of the three tests do not showcase significant deviation within the 
testing period, while there exist some quite distinct peaks in the PSD of the system, which can be considered to correspond to resonant frequencies of the pile-soil system.

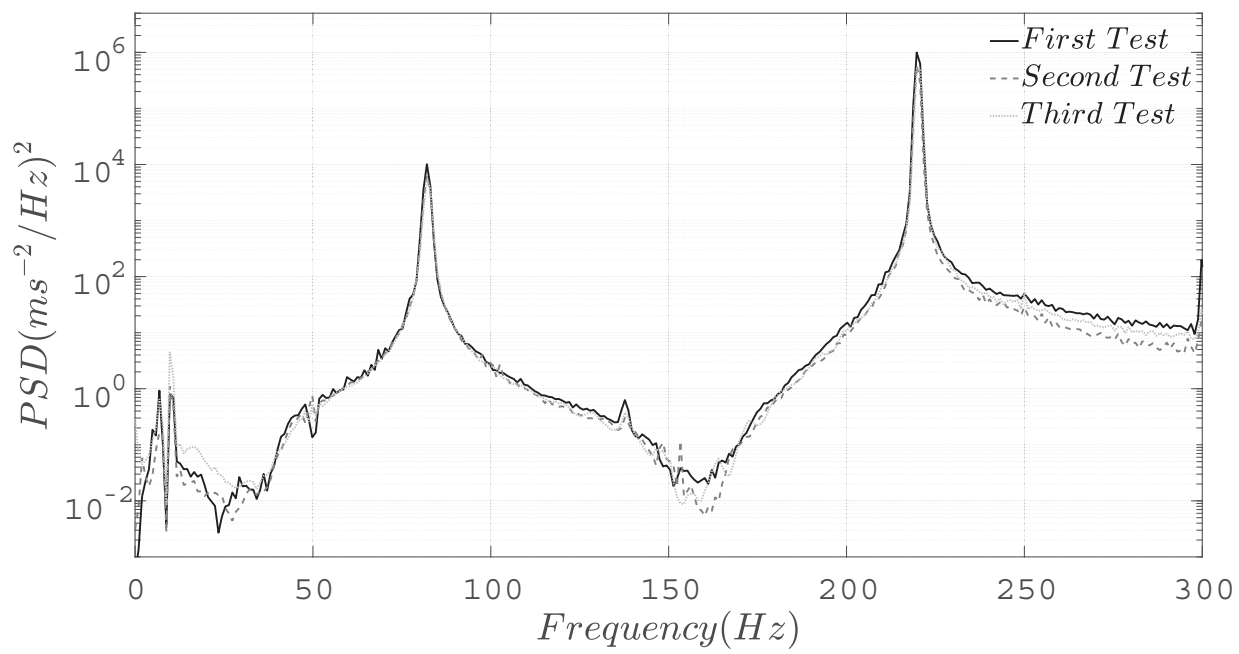

Figure 3: Power spectral density graphs for Pile IH-103 for all testing days

The PSD of the Pile GDP-101 can be seen in Figure 4. Similarly to Pile IH-103, Pile GDP101 does not present significant alteration in its dynamic behaviour within the testing period.

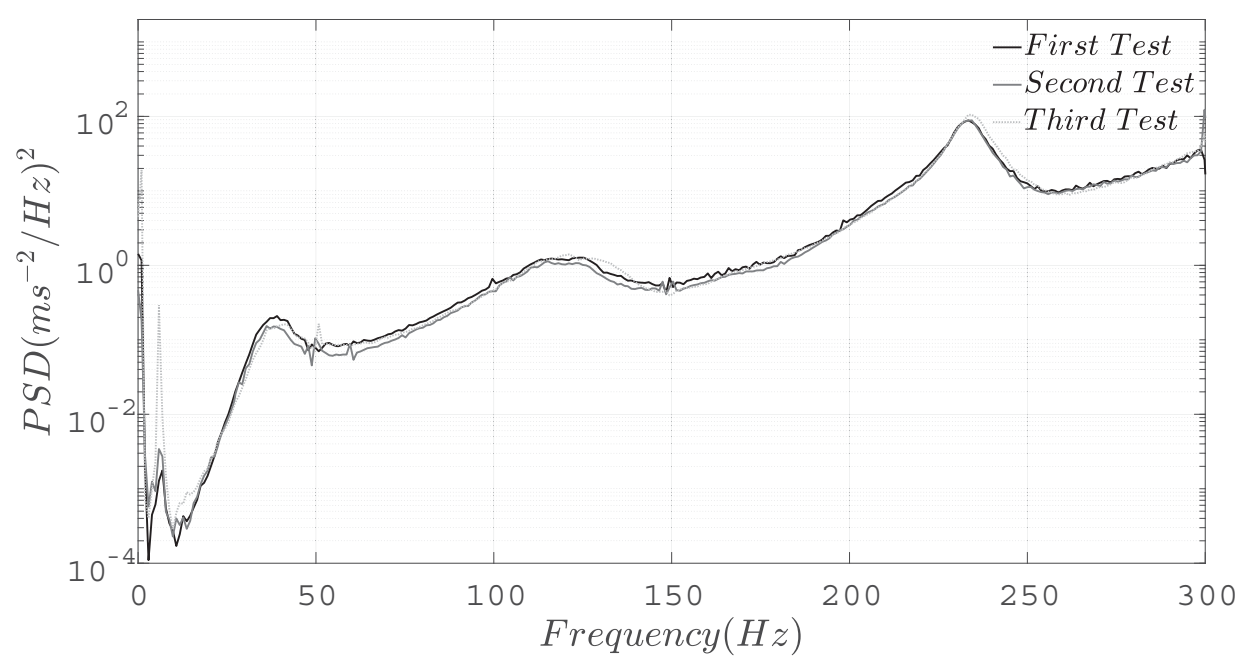

Figure 4: Power spectral density graphs for Pile GDP-101 for all testing days

To showcase the possible differences between the measured properties of the two systems, Figure 5 shows both PSDs of Pile IH-103 and Pile GDP-101, on the last testing day. It is evident that the responses of the two systems are quite dissimilar and though the time evolution of the properties of the two systems was shown to be insignificant in both cases. The difference in magnitude and mainly in the form of the PSDs is an indication of lower damping present in the pile-soil system of Pile IH-103. It needs to be noted that the piles have a structural dissimilarity. Specifically, all piles except the ones driven with impact piling, have a cap welded on the top of the pile, which was used to mount the axial vibratory and the GDP shaker. The effect of this 
cap is not expected to be significant, but is still to be investigated. A final conclusion about the dynamic stiffness of the two systems can thus not be drawn at this stage. However, piles driven with the same installation method, all present identical behaviour. Thus, a consistent observation is made regarding the significant difference in the PSD magnitude and the damping ratio of the IH- and GDP-driven piles.

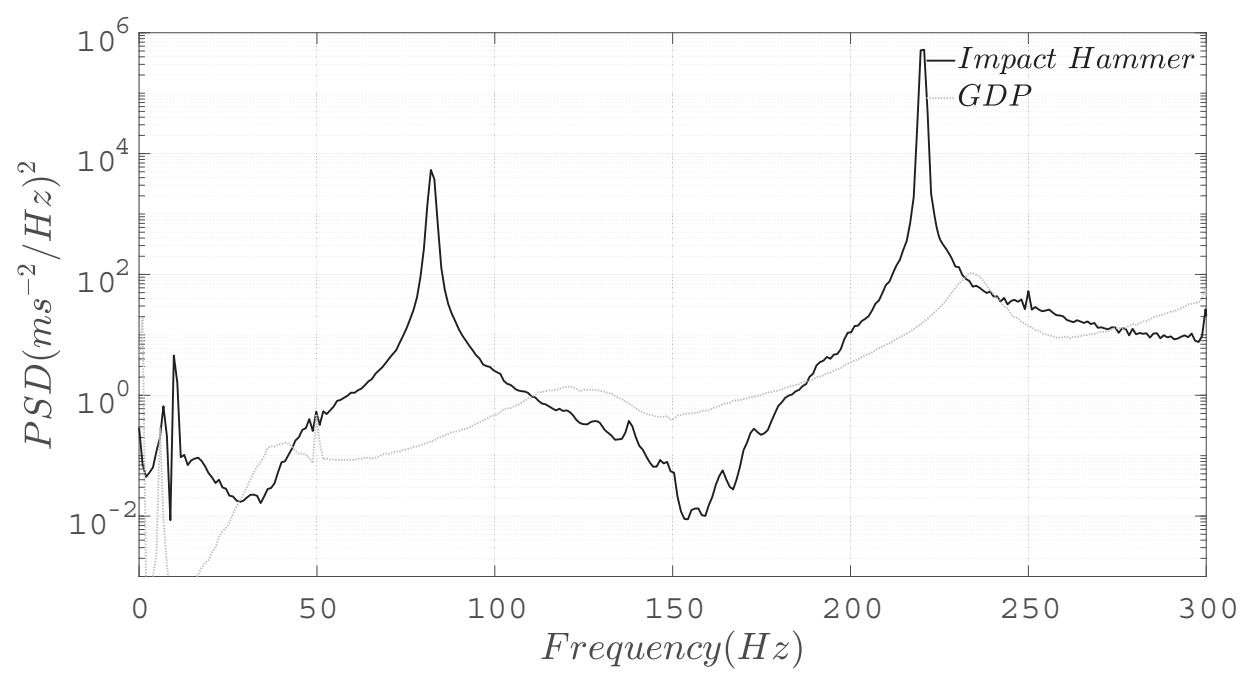

Figure 5: Power spectral density graphs for Pile IH-103 and Pile GDP-101 after the application of lateral loading

The HPBW method presented in Section 2.2 is used to quantify indicative vibration characteristics for Pile IH-103 and Pile GDP-101. In Figure 3, there are two distinct peaks observed in the same frequency and same amplitude for all the tests. Those two peaks are analyzed in Figure 3 and their corresponding natural frequencies $\omega_{n}$ and equivalent viscous damping ratios $\zeta_{e q}$ are presented in Fig. 6.
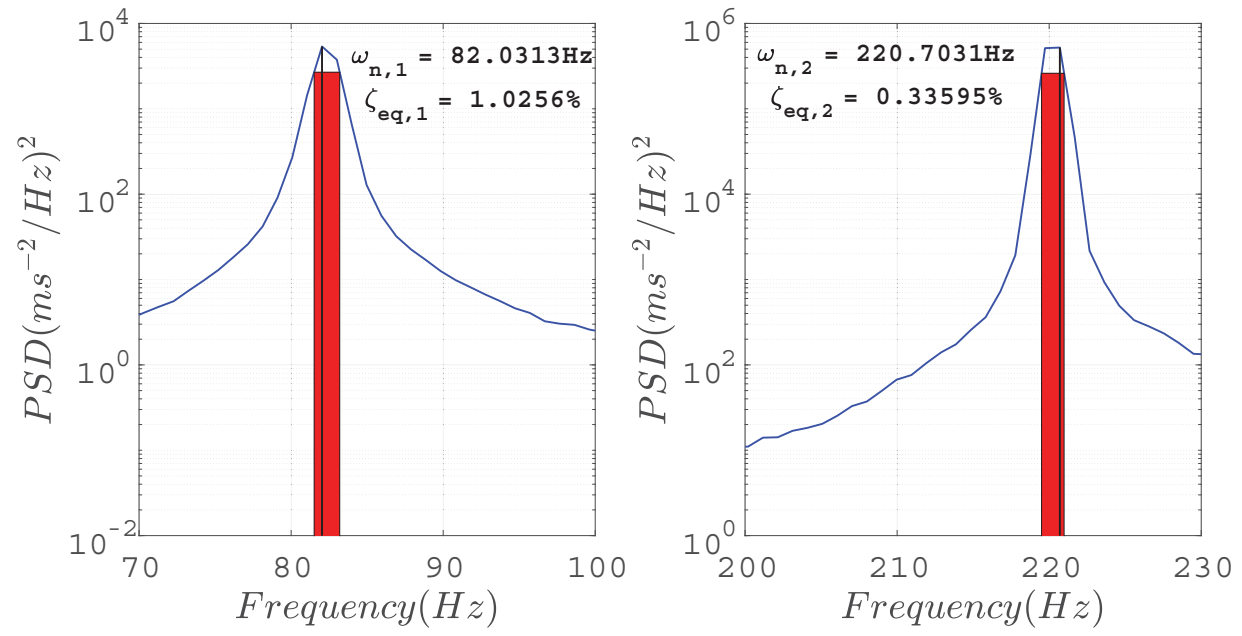

Figure 6: Identification of equivalent viscous damping ratio by the HBWM for Pile IH-103

In the same manner, for the PSDs presented in Figure 4 one peak can be clearly identified, that comprises also the fundamental frequency of the relevant time signal. Similarly to the IH- 
103, the same identification procedure is followed and the respective natural frequency $\omega_{n}$ and equivalent viscous damping ratio $\zeta_{n}$ are given in Figure 7.

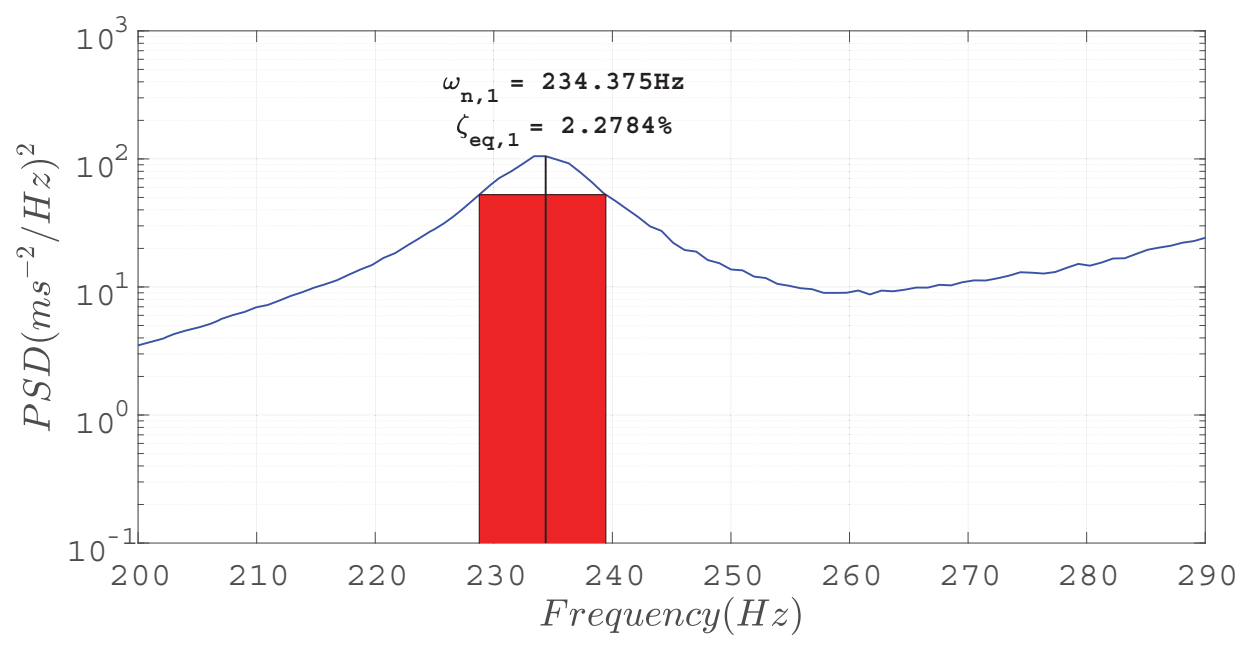

Figure 7: Identification of equivalent viscous damping ratio by the HBWM for Pile GDP-101

In continuation, the effect of the lateral loading is to be addressed by the PSDs of two piles, driven by axial vibratory and GDP techniques respectively. In Figure 8 the PSDs of Pile VH-2, installed with an axial vibratory hammer, are presented for the first and last day of the measurements, indicating prior and post-loading behaviour. The system characteristics, both in frequency and magnitude, indicate a decrease of dynamic stiffness after the application of lateral loading. As can be seen in Figure 8, the form of the PSD is preserved, but a shift to lower frequencies and an increase in magnitude take place, which both indicate a dynamic stiffness decrement. A multitude of reasons may have contributed to that observation, such as creation of a gap between the pile walls and the soil and degradation of the soil in the immediate vicinity of the pile.

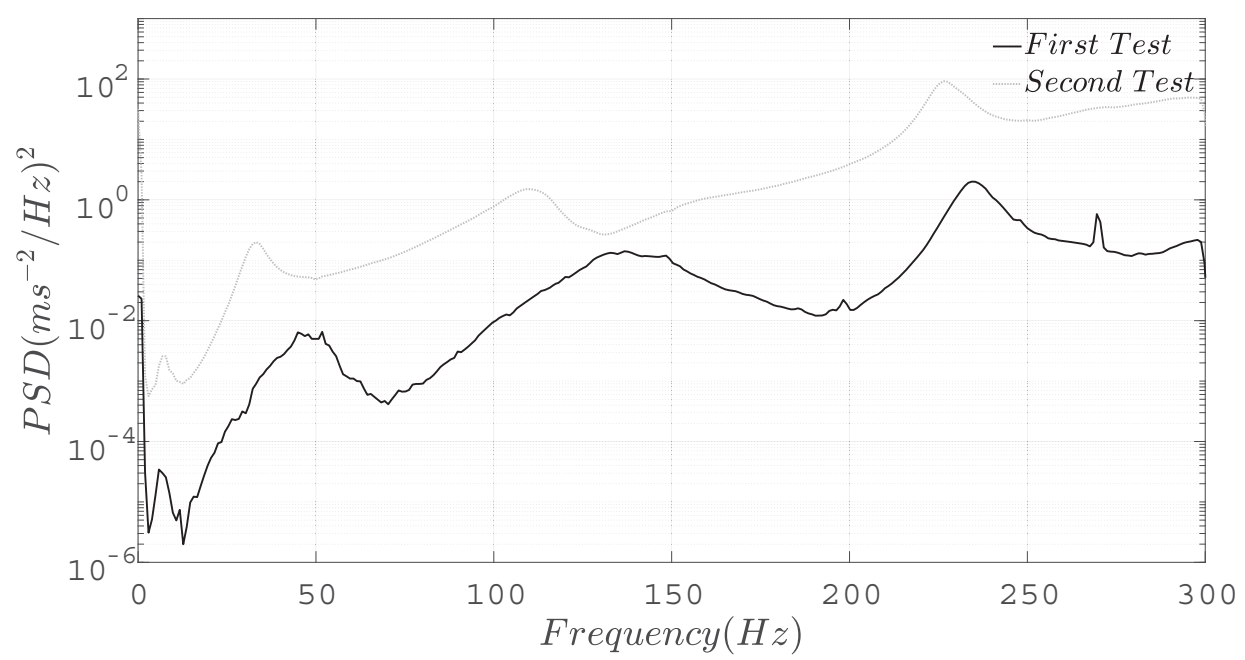

Figure 8: Power spectral density graphs for pile VH-2 in the first and last testing day

A qualitatively similar behaviour can be observed in Figure 9, which refers to Pile GDP-4. 
Albeit, the shift of the PSD form with respect to the frequency is distinguished, no drop in the dynamic stiffness of the system, as was observed in the case of pile $\mathrm{VH}-2$, is seen here.

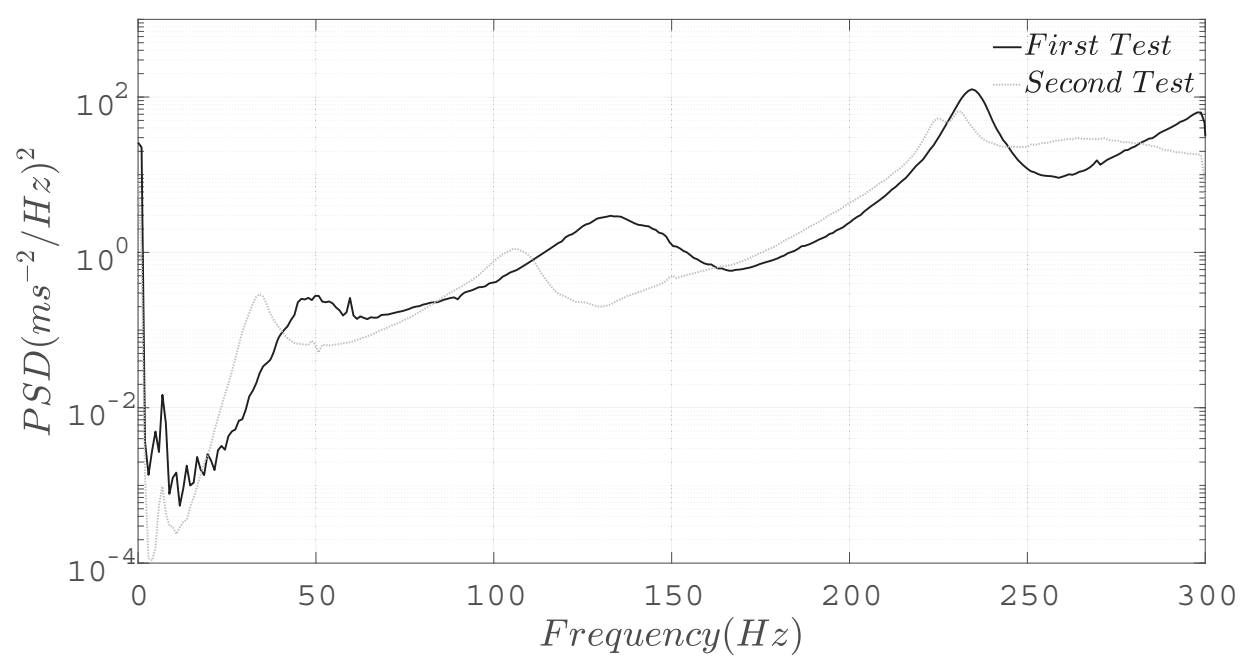

Figure 9: Power spectral density graphs for Pile GDP-4 in the first and last testing day

To investigate the latter observation, a PSD graph including both Pile VH-2 and Pile GDP-4 is presented in Figure 10. By inspection of this figure it can be inferred that the difference in pre- and post-loading behaviour is much greater in the Pile VH-2, compared to that of Pile GDP-4.

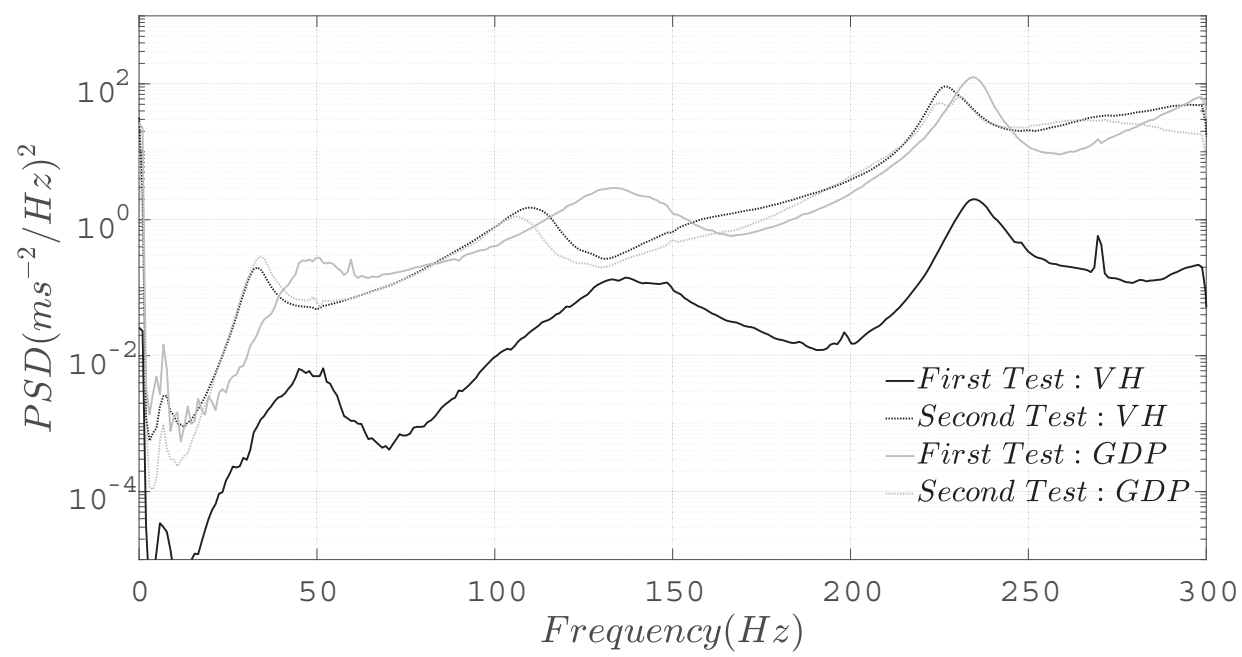

Figure 10: Power spectral density graphs for Pile VH-2 and Pile GDP-4 in the first and last testing day

\section{CONCLUSIONS}

To summarize, the work presented herein comprises a part of a test campaign, conducted in the context of investigating a novel pile driving method, namely the Gentle Driving of Piles (GDP). During the campaign, onshore installation of scaled piles by means of two conventional 
pile driving methods, namely impact piling and axial vibratory driving and the novel GDP method was performed. The proof of concept was successfully accomplished indicating the potential of this novel method to fulfill the originally envisaged goals and motivations.

To realize these objectives, post-installation tests were conducted to examine the various aspects of the behaviour of the pile-soil system with respect to the reference cases of the conventional impact piling and axial vibratory driving. In this work, a part of the post-installation tests, namely impact tests with an instrumented hammer, is briefly discussed. Main objective of this work is to present a collection of selected results of these experimental tests, that can summarize and showcase the dominant trends observed in the majority of the data obtained. Final conclusions were not drawn, but mainly some indications, which will be used to guide a further investigation of the experimental data. A concise consideration of each respective case parameters, accompanied with numerical modeling and used in conjunction with all the available experimental results is intended with the aim to provide a better understanding of all the addressed techniques and predominantly of the GDP method.

\section{Acknowledgements}

This research is associated with the GDP project in the framework of the GROW joint research program. Funding from "Topsector Energiesubsidie van het Ministerie van Econsomische Zaken" under grant number TEHE117100 and financial/technical support from the following partners is gratefully acknowledged: Royal Boskalis Westminster N.V., CAPE Holland B.V., Deltares, Delft Offshore Turbine B.V., Delft University of Technology, ECN, Eneco Wind B.V., IHC IQIP B.V., SHL Offshore Contractors B.V., Shell Global Solutions International B.V., Sif Netherlands B.V., TNO, and Van Oord Offshore Wind Projects B.V.

\section{References}

[1] M Asgarpour. Assembly, transportation, installation and commissioning of offshore wind farms. In Offshore Wind Farms, pages 527-541. Elsevier, 2016.

[2] Jean Chung, Régis Wallerand, and Morgane Hélias-Brault. Pile fatigue assessment during driving. Procedia Engineering, 66:451-463, 2013.

[3] Ben C Gerwick Jr. Construction of marine and offshore structures. CRC press, 2007.

[4] Sergio Sanchez Gomez and AV Metrikine. The energy flow analysis as a tool for identification of damping in tall buildings subjected to wind: Contributions of the foundation and the building structure. Journal of Vibration and Acoustics, 141(1), 2019.

[5] K Lesny and W Richwien. Design, construction and installation of support structures for offshore wind energy systems. In Wind Energy Systems, pages 479-518. Elsevier, 2011.

[6] Rahmatallah Poudineh, Craig Brown, and Benjamin Foley. Global offshore wind market. In Economics of Offshore Wind Power, pages 15-31. Springer, 2017.

[7] S Rodrigues, C Restrepo, E Kontos, R Teixeira Pinto, and P Bauer. Trends of offshore wind projects. Renewable and Sustainable Energy Reviews, 49:1114-1135, 2015.

[8] Kurt Thomsen. Offshore wind: a comprehensive guide to successful offshore wind farm installation. Academic Press, 2014. 
Athanasios Tsetas, Sergio S. Gómez, Apostolos Tsouvalas, Kees van Beek, Faraz S. Tehrani, Evangelos Kementzetzidis, Federico Pisanò, Ahmed Elkadi, Maxim Segeren, Timo Molenkamp and Andrei V. Metrikine

[9] Apostolos Tsouvalas and Andrei V Metrikine. Structure-borne wave radiation by impact and vibratory piling in offshore installations: From sound prediction to auditory damage. Journal of Marine Science and Engineering, 4(3):44, 2016. 